Shinji Takahashi $\mathrm{MD}$, *

Makoto Tanaka MD†

\title{
Reduced efficacy of simulated epidural test doses in sevoflurane- anesthetized adults
}

Purpose: To determine the hemodynamic responses to, and the efficacy of epinephrine-containing epidural test doses, during sevoflurane anesthesia, based on the conventional heart rate (HR) increase 220 beats $\mathrm{min}^{-1}$, the modified HR increase if $\geq 10$ beats $\cdot \mathrm{min}^{-1}$, and the systolic blood pressure (SBP) increase $15 \mathrm{mmHg}$ criteria.

Methods: One hundred and twenty patients were randomised to receive sevoflurane $0.5,1$ or $2 \%$ end-tidal $(n=40$ each) and nitrous oxide $67 \%$ in oxygen after tracheal intubation. Each group of patients was further divided into groups receiving $3 \mathrm{ml}$ lidocaine $1.5 \%$ plus $15 \mu \mathrm{g}$ epinephrine $(1: 200,000) \mathrm{iv}$, or $3 \mathrm{ml}$ normal saline $(n=$ 20 each). The HR and SBP were monitored for four minutes after injection of the study drug.

Results: Intravenous injection of the test dose produced HR increases 220 beats min $^{-1}$ in $18(90 \%), 16(80 \%)$ and $14(70 \%)$ patients at sevoflurane concentrations at $0.5,1$ and $2 \%$, respectively, while those receiving saline developed no HR changes. Based on the modified HR criterion, sensitivity, specificity, and positive and negative predictive values were all $100 \%$ under sevoflurane concentrations of 0.5 and $1 \%$, but not $2 \%$. On the other hand, all patients in the test dose groups and none in the saline groups developed SBP $\geq 15 \mathrm{mmHg}$, ensuring $100 \%$ efficacy based on the conventional SBP criterion under all sevoflurane concentrations studied. In all patients receiving the intravenous test dose, peak HR occurred 30-45 sec earlier than that of SBP.

Conclusion: During stable sevoflurane anesthesia, peak HR increase $\geq 10$ beats $\cdot \mathrm{min}^{-1}$ should be regarded as a positive response with end-tidal sevoflurane concentration $\leq 1 \%$, and peak SBP increase $\geq 15 \mathrm{mmHg}$ is applicable at sevoflurane concentrations between 0.5 and $2 \%$.

Objectif : Déterminer les réponses hémodynamiques à des doses tests péridurales contenant de l'épinéphrine et en vérifier l'efficacité pendant l'anesthésie au sévoflurane. Les essais sont basés sur l'augmentation habituelle de la fréquence cardiaque( $\mathrm{FC})>20$ battements $\mathrm{min}^{-1}$. l'augmentation modifiée de la $\mathrm{FC}$ si $>10$ battements $\mathrm{min}^{-1}$ et le critère d'accroissement $>15 \mathrm{mmHg}$ de la tension artérielle systolique (TAS).

Méthode : Cent vingt patients ont été répartis au hasard et ont reçu du sévoflurane 0,5 , I ou $2 \%$ (fin d'expiration) ( $n=40$ dans chaque groupe) et un mélange de protoxyde d'azote, à $67 \%$, et d'oxygène après l'intubation endotrachéale. Chaque groupe a ensuite été divisé en sous-groupes à qui on a administré $3 \mathrm{ml}$ de lidocaiine $1,5 \%$ et $15 \mu \mathrm{g}$ d'épinéphrine $(1: 200000)$ iv, ou $3 \mathrm{ml}$ de solution salée $(\mathrm{n}=20$ chacun). La FC et la TAS ont été surveillées pendant quatre minutes après l'injection du médicament étudié.

Résultats : Linjection intraveineuse de la dose test a produit une augmentation de la $\mathrm{FC}>20$ battements $\cdot \mathrm{min}^{-}$ chez $18(90 \%), 16(80 \%)$ et $14(70 \%)$ patients pour des concentrations de sévoflurane de 05,1 et $2 \%$, respectivement, tandis que ceux qui ont reçu une solution salée n'ont pas subi de changement de FC. Sur la base du criète modifié de $F C$, la sensibilité, la spécificité et les valeurs prédictives positives et négatives ont été de 100 $\%$ avec les concentrations de sévoflurane de $0,5 \%$ et de $1 \%$ mais non avec la concentration de $2 \%$. Par ailleurs, tous les patients qui ont reçu des doses tests ont développé une TAS $>15 \mathrm{mmHg}$, contrairement aux patients qui ont reçu une solution salée, ce qui assure $100 \%$ d'efficacité, basée sur le critère habituel de TAS, de toutes les concentrations de sévoflurane étudiées. Chez tous les patients qui ont reçu des doses tests intraveineuses, on a enregistré la FC maximale 30-45 s plus tôt que celle de la TAS.

Conclusion : Pendant une anesthésie stable au sévoflurane, l'accroissement de la FC>10 battements $\cdot \mathrm{min}^{-1}$ devrait être considéré comme une réaction positive avec des concentrations de sévoflurane de fin d'expiration $1 \%$, et l'accroissement de TAS maximale $>15 \mathrm{mmHg}$ se manifeste à des concentrations de sévoflurane entre 0,5 et $2 \%$.

From the Departments of Anesthesia, Institute of Clinical Medicine, " University of Tsukuba, Ibaraki, Japan, and Akita University School of Medicine, $\dagger$ Akita, Japan.

Address correspondence to: Dr. Makoto Tanaka, Department of Anesthesia, Akita University School of Medicine, Hondo 1-1-1, Akita-shi, Akita-ken 010-8543, Japan. Phone: 81-18-833-1166 or 834-1111; Fax: 81-18-884-6448; E-mail: mtanaka@med.akita-u.ac.jp Accepted for Publication February 25, 1999 


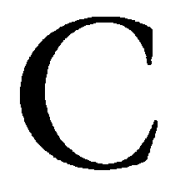

OMBINED epidural-general anesthesia is used increasingly in clinical practice. ${ }^{1}$ In such cases, intravascular migration of the epidural catheter may result, while inadvertent $i v$ injection of a large amount of local anesthetic solution with epinephrine could result in lethal central nervous system or cardiac sequelae. ${ }^{2,3}$

Imperfect positioning of the epidural catheter may be identified with a test dose. However, in a previous study, during isoflurane anesthesia, we demonstrated that a simulated $i v$ injection of a test dose containing 15 $\mu \mathrm{g}$ epinephrine produced unreliable heart rate (HR) increases based on conventional HR criteria (positive $\geq$ 20 beats. $\mathrm{min}^{-1}$ increase), derived from awake, unmedicated healthy volunteers. ${ }^{4,5}$ Since HR variability is depressed during general anesthesia, ${ }^{6}$ a modified HR criterion (positive $\geq 10$ beats $\mathrm{min}^{-1}$ increase) derived from $95 \%$ confidence interval of the peak HR changes after an $i v$ test dose was reliable with isoflurane $\leq 1 \%{ }^{5,7}$ Depression of HR responses during isoflurane anesthesia occurred in a concentration-dependent manner, ie. more profound depression of $\mathrm{HR}$ response at higher isoflurane concentrations. ${ }^{5}$ This is in accordance with in vitro experiments showing direct negative effects of volatile anesthetic agents on the responsiveness of the sino-atrial node to chronotropic agents, such as epinephrine and isoproterenol. ${ }^{8}$

Sevoflurane, a new halogenated volatile anesthetic agent, produces rapid, smooth induction and emergence from anesthesia. ${ }^{9,10}$ Like other volatile agents, sevoflurane acts as a $B$-adrenoceptor antagonist on the pacemaker cells ${ }^{11}$ and conducting system of myocardial tissue. ${ }^{12}$ Therefore, it is likely that the HR response to an ip test dose is similarly depressed during sevoflurane anesthesia as during isoflurane anesthesia. The present study was designed to determine, in a concentration-dependent manner, hemodynamic responses to, and the efficacy of simulated $i v$ test dose in healthy adult patients during sevoflurane anesthesia.

\section{Methods}

This study was approved by our Institutional Research Committee and informed consent was obtained from each patient. One hundred and twenty nonpregnant, ASA I patients scheduled to undergo general anesthesia for elective surgery were studied. None of the patients were taking B-blockers or calcium channel blockers.

After fasting for 8-10 hr, all patients were premedicated with $150 \mathrm{mg}$ ranitidine po $90 \mathrm{~min}$ before induction of general anesthesia, and were subsequently randomly assigned to one of three groups: sevoflurane$0.5 \%, 1.0 \%$ and $2.0 \%(\mathrm{n}=40$ each $)$. In each group, patients were further randomised to receive either $3 \mathrm{ml}$ lidocaine $1.5 \%$ containing $15 \mu \mathrm{g}$ epinephrine $(1: 200,000) i v$ or $3 \mathrm{ml}$ normal saline $(\mathrm{n}=20$ each $) i v$. The anesthesia technique was standardized. On arrival at the operating room, control blood pressure (BP) and HR were obtained noninvasively. An arterial cannula was placed in the radial artery after local anesthetic infiltration for subsequent BP measurements. Lactated Ringer's solution was started and maintained at constant rate of approximately $15 \mathrm{ml} \cdot \mathrm{kg}^{-1} \cdot \mathrm{hr}^{-1}$ throughout the study. Following induction of general anesthesia with $5 \mathrm{mg} \cdot \mathrm{kg}^{-1}$ thiamylal $i p$, tracheal intubation was facilitated with $0.2 \mathrm{mg} \cdot \mathrm{kg}^{-1}$ vecuronium $i v$. Anesthesia was maintained with sevoflurane end-tidal $0.5 \%, 1.0 \%$ or $2.0 \%$ plus nitrous oxide $67 \%$ in oxygen. The lungs were mechanically ventilated using a tidal volume 10 $\mathrm{ml} \cdot \mathrm{kg}^{-1}$ and a respiratory rate $7-10$ breaths $\cdot \mathrm{min}^{-1}$ to maintain $\mathrm{P}_{\mathrm{ET}} \mathrm{CO}_{2} 30-35 \mathrm{~mm} \mathrm{Hg}$ (Excel 210, Ohmeda, Louisville, $\mathrm{CO})$. When three measurements of systolic $\mathrm{BP}$ (SBP) and HR determined at one minute intervals were within $\pm 5 \%$ of the previous value, steady state end-tidal sevoflurane was obtained (no change in endtidal concentration at constant inspiratory concentration for >five minutes), and $>20 \mathrm{~min}$ had elapsed after induction of general anesthesia, either saline or a simulated epidural test dose was injected into a peripheral line over three seconds. The SBP measured invasively and HR obtained from standard lead II electrocardiography were continuously recorded for four minutes after $i v$ injections, and subsequently analysed at $20-\mathrm{sec}$ intervals. Investigators observing hemodynamic changes were blinded to the patient treatment group. At the completion of hemodynamic observations, arterial blood sampling was performed to measure $\mathrm{pH}$, $\mathrm{PaCO}_{2}, \mathrm{PaO}_{2}$, base excess, potassium, ionized calcium, and blood glucose concentrations. All hemodynamic measurements and arterial blood sampling were performed in the supine position before initiation of the scheduled surgery.

Prospectively, an increase in HR was defined as clinically significant if the increase was $\geq 20$ beats. $\mathrm{min}^{-1}$ (conventional HR criterion) ${ }^{4}$ or $\geq 10$ beats. min $^{-1}$ (modified $\mathrm{HR}$ criterion). ${ }^{5,7}$ An increase in SBP $\geq 15 \mathrm{mmHg}$ was regarded as clinically significant (SBP criterion). ${ }^{4}$ In addition to maximum HR and SBP responses, sensitivity, specificity, and positive $(+P V)$ and negative predictive values (-PV) were determined based on the hemodynamic criteria. Sensitivity was calculated as the number of true-positives divided by the number of true-positives plus false-negatives; specificity was the number of true negatives divided by the number of true negatives plus false-positives; positive predictive value $(+\mathrm{PV})$ was the number of true positives divided by the number of true 

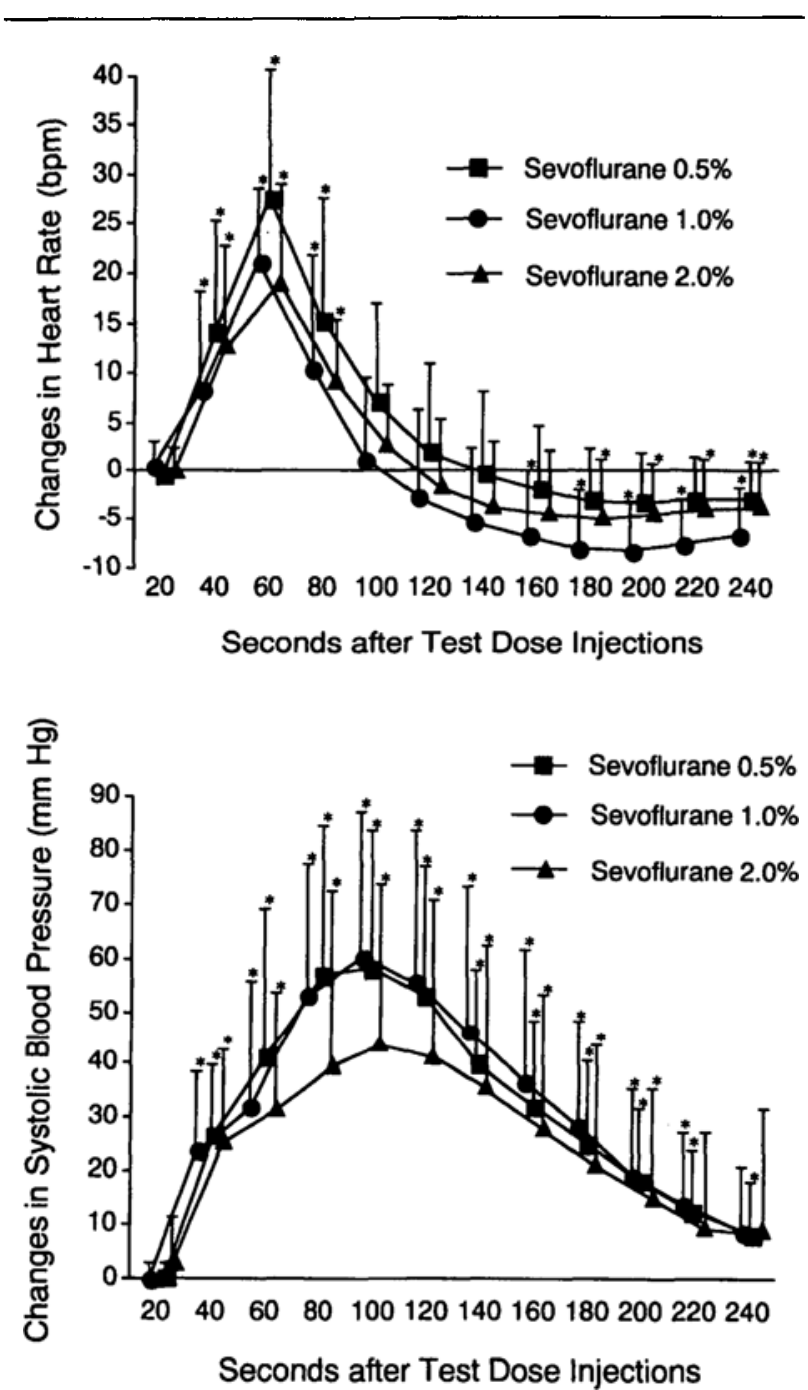

FIGURE Changes in heart rate (upper panel) and systolic blood pressure (lower panel) after $i v$ injection of the test dose consisting of $3 \mathrm{ml}$ lidocaine $1.5 \%$ plus $15 \mu \mathrm{g}$ epinephrine $(1: 200,000)$ in healthy adult patients anesthetized with end-tidal sevoflurane $0.5,1.0$ and $2.0 \%(n=20 \mathrm{each})$ and nitrous oxide in oxygen before surgery. Values are mean $\pm \mathrm{SD}$. ${ }^{*} P<0.05$ vs baseline (preinjection) values.

positives plus false-positives; negative predictive value $(-P V)$ was the number of true negatives divided by the number of true negatives plus false-negatives.

A power analysis based on a previous report revealed that more than 16 patients would provide a power greater than $0.8(P=0.05)$ for detection of a $25 \%$ difference in paired hemodynamic responses. ${ }^{4}$ All data are expressed as mean \pm SD. Patient demographic and hemodynamic data were compared using chisquared test or unpaired Student's $t$ test with Bonferroni's correction to adjust for multiple compar- isons. Pair-wise hemodynamic data in each group were analysed first by repeated-measures analysis of variance followed by paired Student $t$ test with Bonferroni's correction. Correlations between patients' demographic data, epinephrine dose and baseline HR vs hemodynamic changes were examined using Pearson's correlation coefficient. A $P$ value $<0.05$ was considered statistically significant.

\section{Results}

There were no differences among the sevoflurane groups in terms of demographic data, and preinduction and baseline (preinjection) BP and HR (Table I). Baseline BP immediately before the simulated epidural test dose injection during general anesthesia was less than the preinduction values within each group $(P<$ 0.01 ), while baseline HR in the sevoflurane 0.5 and $1.0 \%$ groups was less than the preinduction values $(P$ $<0.05$ ). Baseline SBP in the sevoflurane $2.0 \%$ group was smaller than in the sevoflurane 0.5 and $1.0 \%$ groups $(P<0.05)$. No differences in these variables were seen between the test dose and saline groups at each sevoflurane concentration (data not shown).

Intravenous injection of the test dose caused biphasic changes in HR in all groups, ie. initial increases followed by subsequent decreases (Figurc 1), while iv saline caused no hemodynamic alteration. Increases compared with the baseline values in HR were seen in all groups within interval of $40-80 \mathrm{sec}$ after test dose injections, while $\mathrm{HR}$ decreases were seen in the sevoflurane $0.5,1.0$ and $2.0 \%$ groups within intervals of $240,160-240$, and 180-240 sec, respectively. Mean maximum increases (ranges) in $\mathrm{HR}$ in the sevoflurane $0.5,1.0$, and $2.0 \%$ groups were $34 \pm 13(18-68), 25 \pm$ $9(10-44)$, and $24 \pm 13(5-46)$ beats $\mathrm{min}^{-1}$, which occurred at $59 \pm 9(37-78), 62 \pm 9(47-80)$, and $55 \pm$ $9(38-72) \mathrm{sec}$ after test dose injections, respectively.

The SBP changes were monophasic, and increases from baseline values were observed within the intervals of 40-240, 40-220, and 40-200 sec after test dose injections in the sevoflurane-0.5, - 1.0 , and $-2.0 \%$ groups, respectively (Figure 1). Mean maximum increases (ranges) in SBP were $63 \pm 26(20-106), 65$ $\pm 26(28-114)$, and $53 \pm 28(15-131) \mathrm{mmHg}$, which occurred at $94 \pm 18(73-130), 100 \pm 18(60-123)$, and $95 \pm 25(48-135) \mathrm{s}$ after test dose injections, respectively. Five $(25 \%)$, five $(25 \%)$ and two $(10 \%)$ patients in the sevoflurane $0.5,1.0$, and $2.0 \%$ groups, respectively, developed SBP greater than $180 \mathrm{mmHg}$.

In those receiving $i v$ test doses in the sevoflurane 0.5 , 1.0 , and $2.0 \%$ groups, 18,16 , and 14 (of 20 patients), respectively, developed maximum HR increments $\geq 20$ beats. $\mathrm{min}^{-1}$, while all parients in the saline groups had a 
TABLE I Patient characteristics, and preinduction and baseline blood pressure and heart values

\begin{tabular}{|c|c|c|c|}
\hline & Sevoflurane-0.5\% $(n=40)$ & Sevoflurane-1.0\% $(n=40)$ & Sepoflurane-2.0\% $(n=40)$ \\
\hline Age (yr) & $42 \pm 11$ & $43 \pm 13$ & $42 \pm 14$ \\
\hline Weight (kg) & $57 \pm 10$ & $57 \pm 9$ & $58 \pm 11$ \\
\hline Height $(\mathrm{cm})$ & $160 \pm 8$ & $162 \pm 8$ & $161 \pm 10$ \\
\hline Sex (male / female) & $18 / 22$ & $18 / 22$ & $17 / 23$ \\
\hline \multicolumn{4}{|l|}{ Preinduction ${ }^{2}$} \\
\hline SBP (mmHg) & $129 \pm 13$ & $131 \pm 17$ & $129 \pm 14$ \\
\hline $\mathrm{DBP}(\mathrm{mmHg})$ & $81 \pm 10$ & $79 \pm 12$ & $79 \pm 9$ \\
\hline HR (beats. $\min ^{-1}$ ) & $75 \pm 13$ & $72 \pm 12$ & $74 \pm 13$ \\
\hline \multicolumn{4}{|l|}{ Baseline $^{b}$} \\
\hline SBP (mmHg) & $106 \pm 13^{*}$ & $102 \pm 12^{*}$ & $95 \pm 11 * \dagger$ \\
\hline $\mathrm{DBP}(\mathrm{mmHg})$ & $62 \pm 9^{*}$ & $59 \pm 8^{*}$ & $58 \pm 10^{*}$ \\
\hline HR (beats. $\min ^{-1}$ ) & $66 \pm 12^{\star}$ & $66 \pm 11^{*}$ & $71 \pm 12$ \\
\hline
\end{tabular}

Values are mean $\pm S D$ or numbers.

${ }^{a}$ Obtained immediately before induction of general anesthesia; ${ }^{b}$ Obtained immediately before study drug injections.

$\mathrm{SBP}=$ systolic blood pressure, $\mathrm{DBP}=$ diastolic blood pressure, $\mathrm{HR}=$ heart rate

$* P<0.05$ vs preinduction valucs.

$\dagger P<0.05$ vs sevoflurane 0.5 and $1.0 \%$

TABLE II Sensitivity, specificity, and positive and negative predictive values of epidural test dose containing $15 \mu g$ epinephrine based on the peak heart rate and systolic blood pressure in adult patients during stable $0.5 \%, 1.0 \%$, and $2.0 \%$ end-tidal sevoflurane and nitrous oxide anesthesia

\begin{tabular}{|c|c|c|c|}
\hline Group & Sevoflurane- $0.5 \%$ & Sevoflurane-1.0\% & Sevoflurane-2.0\% \\
\hline \multicolumn{4}{|c|}{ Heart rate criterion ( 220 beats $\left.\cdot \mathrm{min}^{-1}\right)$} \\
\hline Sensitivity & $90 \%(18 / 20)$ & $80 \%(16 / 20)$ & $70 \%(14 / 20)$ \\
\hline Specificity & $100 \%(20 / 20)$ & $100 \%(20 / 20)$ & $100 \%(20 / 20)$ \\
\hline Positive predictive value & $100 \%(18 / 18)$ & $100 \%(16 / 16)$ & $100 \%(14 / 14)$ \\
\hline Negative predictive value & $91 \%(20 / 22)$ & $83 \%(20 / 24)$ & $77 \%(20 / 26)$ \\
\hline \multicolumn{4}{|c|}{ Heart rate criterion ( 210 beats $\mathrm{min}^{-1}$ ) } \\
\hline Sensitivity & $100 \%(20 / 20)$ & $100 \%(20 / 20)$ & $95 \%(19 / 20)$ \\
\hline Specificity & $100 \%(20 / 20)$ & $100 \%(20 / 20)$ & $100 \%(20 / 20)$ \\
\hline Positive predictive value & $100 \%(20 / 20)$ & $100 \%(20 / 20)$ & $100 \%(19 / 19)$ \\
\hline Negative predictive value & $100 \%(20 / 20)$ & $100 \%(20 / 20)$ & $95 \%(20 / 21)$ \\
\hline \multicolumn{4}{|c|}{ Systolic blood pressure criterion ( $215 \mathrm{mmHg}$ ) } \\
\hline Sensitivity & $100 \%(20 / 20)$ & $100 \%(20 / 20)$ & $100 \%(20 / 20)$ \\
\hline Specificity & $100 \%(20 / 20)$ & $100 \%(20 / 20)$ & $100 \%(20 / 20)$ \\
\hline Positive predictive value & $100 \%(20 / 20)$ & $100 \%(20 / 20)$ & $100 \%(20 / 20)$ \\
\hline Negative predictive value & $100 \%(20 / 20)$ & $100 \%(20 / 20)$ & $100 \%(20 / 20)$ \\
\hline
\end{tabular}

Values are percentages (numbers).

maximum HR increase $<20$ beats- $\mathrm{min}^{-1}$. Therefore, sensitivity / specificity / $+\mathrm{PV} / \mathrm{-PV}$ based on the conventional HR criterion in the sevoflurane $0.5,1.0$, and $2.0 \%$ groups were $90 / 100 / 100 / 91 \%, 80 / 100 / 100 /$ $83 \%$, and $70 / 100 / 100 / 77 \%$, respectively (Table II). Based on the modified HR criterion, sensitivity / specificity / +PV / -PV in the sevollurane $0.5,1.0$, and $2.0 \%$ groups were $100 / 100 / 100 / 100 \%, 100 / 100 / 100$ $/ 100 \%$, and $95 / 100 / 100 / 95 \%$, respectively (Table II). On the other hand, none of the patients receiving saline and all those receiving the $i v$ test dose developed maximum SBP increments $15 \mathrm{mmHg}$, resulting in sensitivities, specificities, $+\mathrm{PV}$ and $-\mathrm{PV} 100 \%$ at all sevoflurane concentrations studied.

None of the patients developed hypoxemia $\left(\mathrm{PaO}_{2} \leq\right.$ $100 \mathrm{mmHg})$, hypercarbia $\left(\mathrm{PaCO}_{2} \geq 45 \mathrm{mmHg}\right)$, hypocarbia $\left(\mathrm{PaCO}_{2}<30 \mathrm{mmHg}\right)$, or hypoglycemia (blood glucose $\leq 80 \mathrm{mg} \cdot \mathrm{dL}^{-1}$ ). Plasma potassium and ionized calcium concentrations were within normal ranges in all patients. No correlations were demon- 
strated between the maximum changes in $\mathrm{HR}$ Ds age, body weight, epinephrine dose in $\mathrm{mg} \cdot \mathrm{kg}^{-1}$, or baseline HR within each group. No arrhythmia associated with epinephrine injection was observed in any patient.

\section{Discussion}

The present study has demonstrated that the conventional HR criterion is unreliable in detecting iv injection of lidocaine plus $15 \mu \mathrm{g}$ epinephrine during stable sevoflurane $0.5-2.0 \%$ anesthesia. On the other hand, modification of the HR threshold to 10 beats $\mathrm{min}^{-1}$ during sevoflurane $\leq 1 \%$ as well as the conventional SBP criterion at end-tidal sevoflurane concentration $\leq 2 \%$ seem to be appropriate, since no false-positives or false-negatives were observed.

We have shown in a previous similar study using isoflurane, that the HR response to iv injection of the same test dose was depressed in a concentration-dependent manner. ${ }^{5}$ During approximately 0.5 MAC isoflurane, $100 \%$ sensitivity and specificity were obtained based on the conventional $\mathrm{HR}$ criterion. In the present study, however, the efficacy did not reach $100 \%$ even at 0.25 MAC of sevoflurane based on the same HR threshold. Therefore, it is likely that sevoflurane depresses the maximum $\mathrm{HR}$ response to epinephrine to a greater extent than isoflurane at equipotent concentrations, although no comparative study has been made.

Optimal drugs, doses, methods, and the efficacy of epidural test doses continue to be sought during general anesthesia. Previous studies demonstrated that isoproterenol, as a chronotropic marker, produced more reliable HR changes than epinephrine in isofluraneanesthetized patients, ${ }^{13}$ even though the issue of neurotoxicity associated with epidural isoproterenol and hypotension due to $i v$ isoproterenol may limit its clinical usefulness at the present time. ${ }^{14}$ Efficacy of air in detecting intravascular injection has been determined in labouring women, ${ }^{15}$ and changes in skin perfusion, ${ }^{16}$ but not temperature, after an epidural test dose seemed to be a reliable predictor of correct catheter placement. However, these procedures require Doppler equipment, and may not be applicable in certain surgical procedures. Moreover, T-wave amplitude is known to change in response to physical and mental stress, ${ }^{17}$ iv infusion of epinephrine, ${ }^{18}$ and absorption of epinephrine-containing lidocaine during brachial plexus blockade. ${ }^{19}$ Whether changes in T-wave morphology could be a reliable marker during general anesthesia, and the efficacy for $i v$ injection of the test dose based on such novel criteria remain to be determined.

Interpretation of the present results should be confined to the dose of epinephrine employed in our study: failure to demonstrate reliable $\mathrm{HR}$ increments during sevoflurane anesthesia may have been due to an inadequate dose of epinephrine. However, in our previous study, $22.5 \mu \mathrm{g}$ epinephrine iv augmented the SBP response compared with $15 \mu \mathrm{g}$ epinephrine during isoflurane $1 \%$, but not the HR response, possibly as a result of greater baroreflex-mediated slowing of HR. ${ }^{5}$ On the other hand, $7.5 \mu$ g epinephrine $i v$ elicited insufficient SBP and HR responses according to any hemodynamic criterion. ${ }^{5}$ Given the fact that in awake, unmedicated volunteers, 10 or $15 \mu \mathrm{g}$ epinephrine reliably produces $\mathrm{HR}$ increases 220 beats $\mathrm{min}^{-1}$, and the HR response to iv epinephrine is profoundly depressed under general anesthesia, it seems reasonable to assume that at least $15 \mu \mathrm{g}$ epinephrine should be used as a component of the test dose to demonstrate clinically detectable hemodynamic responses.

A previous report by $\mathrm{Liu}^{20}$ demonstrated that high thoracic epidural-general anesthesia depressed both $\mathrm{HR}$ and SBP responses to an ip test dose containing $15 \mu \mathrm{g}$ epinephrine, when compared with low thoracic epiduralgeneral anesthesia and during awake state. On the other hand, Gieraerts et al. ${ }^{21}$ showed that in labouring women sensitivity and specificity remained unchanged after lowthoracic epidural analgesia was established. These observations imply that our present results could be influenced by the extent of epidural neural blockade, especially if the block level reached high thoracic dermatomes. In addition, regression of epidural analgesia and concomitant surgical stimulation may lead to a false positive response to a test dose injection. Ultimate validation of these hemodynamic criteria, therefore, require clinical trial during surgery when reinforcing doses of epidural local anesthetic are needed. Furthermore, the use of multiholed epidural catheter would make clinical judgment of intravascular migration of the catheter difficult, since only a part of local anesthetic solution may be injected intravascularly. Until more reliable methods are identi- fied irrespective of the anesthetic technique, the depth of general anesthesia, and the presence and extent of epidural neural blockade, a "top-up" dose of local anesthetic with or without epinephrine should be given slowly in incremental manner while close attention is being paid on hemodynamic changes following each dose.

Whether an arterial line should be placed in all patients during combined epidural-general anesthesia remains to be debated. One disadvantage of the oscillometric method is its inherent errors associated with BP determinations. Indeed, Borow and Newburger compared the difference in SBP between noninvasive and invasive methods in patients undergoing cardiac catheterization, and found almost a $10 \mathrm{mmHg}$ difference in the maximal difference of SBP with a percent mean maximal error of $1 \%-3 \%$ within subjects. ${ }^{22}$ These 
results imply that when clinical judgment is based solely on the peak SBP measured noninvasively, such errors may lead to increased false positive or negative responses. Furthermore, the frequency of BP measurements with a noninvasive method is usually limited to 30-60 sec. Hence, a brief SBP change may be missed even with frequent $\mathrm{BP}$ measurement. One can also argue that the clinical applicability of our criteria may be limited when the test dose is administered before the steady state end-tidal sevoflurane was achieved. Even though the partial pressure of sevoflurane at the effector organ cannot be accurately predicted from the endtidal sevoflurane concentration, it is considered to be lower than that of end-tidal concentration. In such cases, hemodynamic responses to $i v$ test doses would be greater than anticipated from the simultaneous endtidal sevoflurane concentration.

In conclusion, based on the conventional HR criterion (positive if $\geq 20$ beats $\mathrm{min}^{-1}$ increase), an epidural test dose consisting of $3 \mathrm{ml}$ lidocaine $1.5 \%$ plus $15 \mu \mathrm{g}$ epinephrine is an inadequate marker for detecting intravascular injection in adult patients during sevoflurane and nitrous oxide anesthesia. The modified HR criterion (positive if $\geq 10$ beats. $\mathrm{min}^{-1}$ increase) was reliable under end-tidal sevollurane $\leq 1 \%$, while the SBP criterion (positive if $\geq 15 \mathrm{mmHg}$ increase) gave $100 \%$ efficacy at sevoflurane concentrations between $0.5-2 \%$.

\section{References}

1 Liu S, Carpenter RL, Neal JM. Epidural anesthesia and analgesia. Their role in postoperative outcome.

Anesthesiology 1995; 82: 1474-506.

2 Marx GF. Cardiotoxicity of local anesthetics - the plot thickens (Editorial). Anesthesiology 1984; 60: 3-5.

3 Matsumiya N, Dobi S, Takahashi H, Kondo $\Upsilon$, Naito $H$. Cardiovascular collapse in an infant after caudal anesthesia with a lidocaine-epinephrine solution. Anesth Analg 1986; 65: 1074-6.

4 Guinard J-P, Mulroy MF, Carpenter RL, Knopes KD. Test doses: optimal epinephrine content with and with out acute beta-adrenergic blockade. Anesthesiology 1990; 73: 386-92.

5 Tanaka M, Takabashi S, Kondo T, Matsumiya $N$. Efficacy of simulated epidural test doses in adult patients anesthetized with isoflurane: a dose-response study. Anesth Analg 1995; 81: 987-92.

6 Donchin $\Upsilon$, Feld JM, Porges SW. Respiratory sinus arrhythmia during recovery from isoflurane-nitrous oxide anesthesia. Anesth Analg 1985; 64: 811-5.

7 Ware PD, Lin SS. Efficacy of epidural test doses (Letter). Anesth Analg 1996; 82: 1304-5.

8 Stowe DF, Dujic Z, Bosnjak ZJ, Kalbfleisch JH, Kampine $J P$. Volatile anesthetics attenuate sympathomimetic actions on the guinea pig SA node. Anesthesiology 1988; 68: 887-94.

9 Lerman J, Sikich N, Kleinman S, Yentis S. The pharmacology of sevoflurane in infants and children. Anesthesiology 1994; 80: 814-24.

10 Yasuda N, Targ AG, Eger EI II. Solubility of I-653, sevoflurane, isoflurane and halothane in human tissues. Anesth Analg 1989; 69: 370-3.

11 Sanuki $M$, Yuge O, Kawamoto M, Fujii K, Azuma T. Sevoflurane inhibited $B$-adrenoceptor-G protein bindings in myocardial membrane in rats. Anesth Analg 1994; 79: 466-71.

12 Weigt $H U$, Kowok W-M, Rebmert GC, Turner LA, Bosnjak ZJ. Voltage-dependent effects of volatile anesthetics on cardiac sodium current Anesth Analg 1997; 84: 285-93.

13 Tanaka $M$. Epidural test dose: isoproterenol is a reliable marker for intravascular injection in anesthetized adults. Anesth Analg 1996; 82: 1056-9.

14 Tanaka $M$. Simulation of an epidural test dose with intravenous isoproterenol in isoflurane-anesthetized adults. Anesth Analg 1997; 85: 639-43.

15 Leighton BL, Norris $M C$, DeSimone CA, Rosko T, Gross $J B$. The air test as a clinically useful indicator of intravenously placed epidural catheters. Anesthesiology 1990; 73: 610-3.

16 Valley MA, McKenzie AM, Bourke DL, Raja SN. Effects of epidural test dose volume on skin perfusion, temperature, and reflex vasoconstriction. Reg Anesth 1994; 19: 52-8.

17 Hijzen TH, Slangen JL. The electrocardiogram during emotional and physical stress. Int J Psychophysiol 1985 ; 2 : 273-9.

18 Fisher QA, Shaffner DH, Yaster M. Detection of intravascular injection of regional anaesthetics in children. Can J Anaesth 1997; 44: 592-8.

19 Kubota Y, Toyoda Y, Kubota H, Asada A. Epinephrine in local anesthetics does indeed produce hypokalemia and ECG changes (Letter). Anesth Analg 1993; 77: 867.

20 Liu SS. Hemodynamic responses to an epinephrine test dose in adults during epidural or combined epiduralgeneral anesthesia. Anesth Analg 1996; 83: 97-101.

21 Gieraerts $R$, Van Zundert $A$, De Wolf $A$, Vaes $L$. Ten ml bupivacaine $0.125 \%$ with $12.5 \mu \mathrm{g}$ epinephrine is a reliable epidural test dose to detect inadvertent intravascular injection in obstetric patients. A double-blind study. Acta Anaesthesiol Scand 1992; 36: 656-9.

22 Borow KM, Newburger JW. Noninvasive estimation of central aortic pressure using the oscillometric method for analyzing systemic artery pulsatile blood flow: comparative study of indirect systolic, diastolic, and mean brachial artery pressure with simultaneous direct ascending aortic pressure measurements. Am Heart J 1982; 103: 879-86. 